Loma Linda University

TheScholarsRepository@LLU: Digital Archive of Research, Scholarship \& Creative Works

Loma Linda University Electronic Theses, Dissertations \& Projects

$3-1-2011$

\title{
Body Objectification and Elective Cosmetic Procedures in African American Women
}

Allycin Powell-Hicks

Loma Linda University

Follow this and additional works at: http://scholarsrepository.llu.edu/etd

Part of the Psychology Commons

\section{Recommended Citation}

Powell-Hicks, Allycin, "Body Objectification and Elective Cosmetic Procedures in African American Women" (2011). Loma Linda University Electronic Theses, Dissertations \& Projects. 56.

http://scholarsrepository.llu.edu/etd/56

This Thesis is brought to you for free and open access by TheScholarsRepository@LLU: Digital Archive of Research, Scholarship \& Creative Works. It has been accepted for inclusion in Loma Linda University Electronic Theses, Dissertations \& Projects by an authorized administrator of TheScholarsRepository@LLU: Digital Archive of Research, Scholarship \& Creative Works. For more information, please contact scholarsrepository@llu.edu. 
LOMA LINDA UNIVERSITY

School of Science and Technology

In conjunction with the

Faculty of Graduate Studies

Body Objectification and Elective Cosmetic Procedures in African American Women

by

Allycin Powell-Hicks

A Thesis submitted in partial satisfaction of

The requirements for the degree of Master of Arts in General Psychology

March 2011 
(C)2011

Allycin Powell-Hicks

All Rights Reserved 
Each person whose signature appears below certifies that this dissertation in his/her opinion is adequate, in scope and quality, as a dissertation for the degree of Master of Arts.

, Chairperson

Gloria Cowan, Professor of Psychology, California State University, San Bernardino

Kandal Boyd, Associate Professor of Psychology

Andy Lampkin, Associate Professor of, School of Religion 


\section{ACKNOWLEDGEMENTS}

I would like to extend my heart-felt gratitude to all that have inspired me to reach for my dreams no matter how difficult they may seem. Thanks for the support, mentoring, pep talks, and patient assistance. Without you my love for answering the universe's questions would be unfounded and misplaced. Firstly, I would like to thank my parents Dr. Calvin Hicks and Dr. Cynthia Powell-Hicks, they have fostered my curiosity my whole life. Secondly, I would like to thank my sisters Shelby and Kyndall Powell-Hicks for giving me the support to reach my goals. Finally, I would like to thank

my grandparents who have given me advice and knowledge, Alice and Joseph Powell and Viola Hicks.

Next I wanted to thank my Thesis committee beginning with my chair, Dr. Gloria Cowan, for her undying support of my research dream. Your dedication to the study of women and wonderful spirit are truly gifts to all of those around you. I thank my committee for being so dedicated to my study, their constant support and gentle guidance was extremely appreciated, thank you Dr. Andrew Lampkin and Dr. Kendal Boyd.

Thank you to all of the other momentous women in my life, thank you Alpha Kappa Alpha Sorority Inc. and Kansas Ave Seventh-day Adventist Church. Finally I thank the cosmetic surgeons, hair stylists, and people that facilitated my data collection with a special thank you to Dr. Allen Gabriel the Director of Research in the Department of Plastic Surgery at Loma Linda University. 


\section{CONTENT}

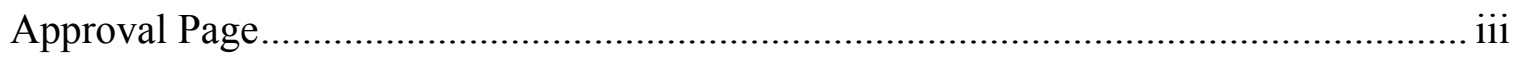

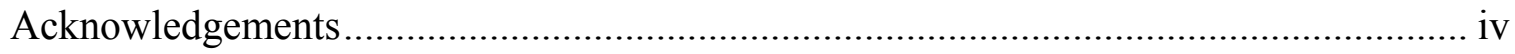

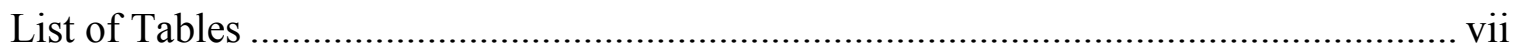

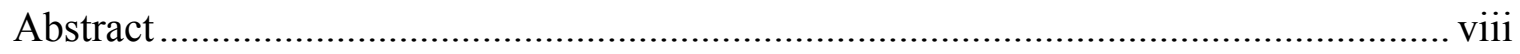

Chapter

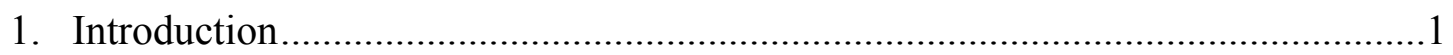

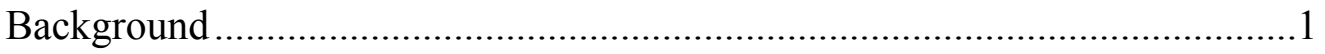

Evolutionary Theory/Natural Selection ....................................................

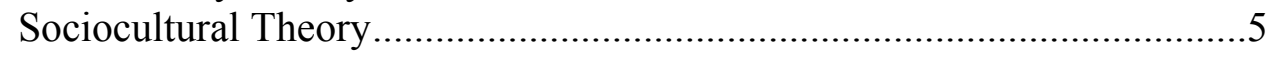

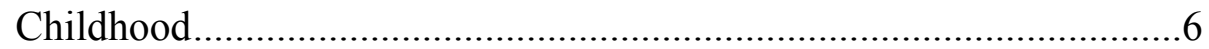

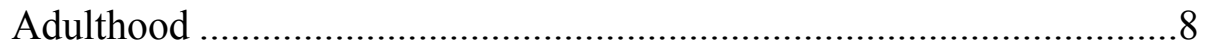

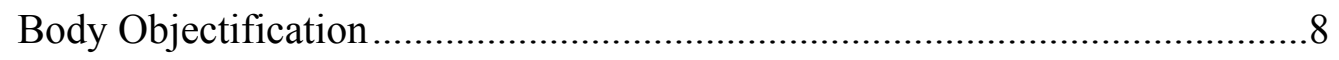

African American Women.......................................................................12

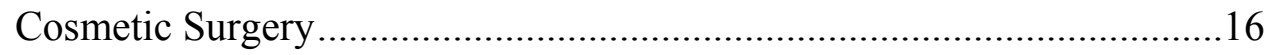

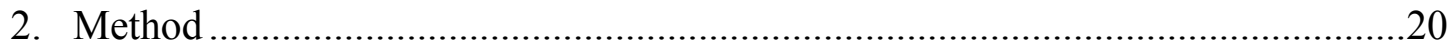

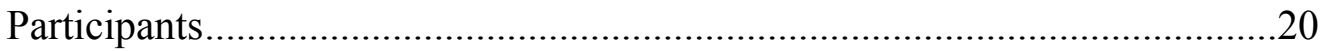

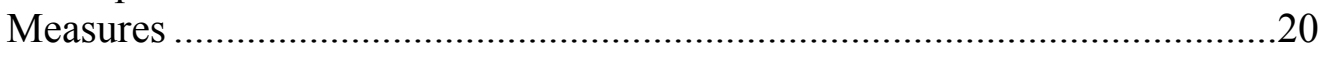

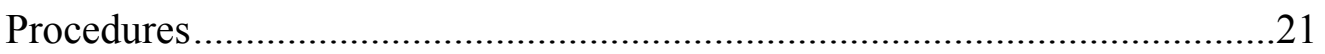

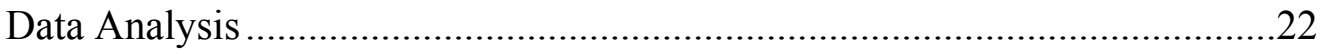

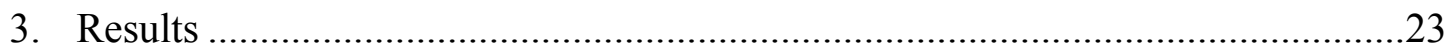

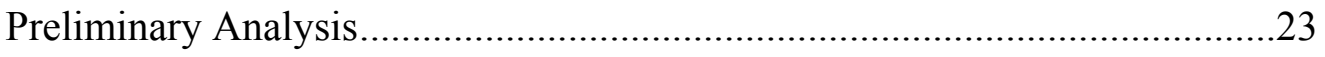

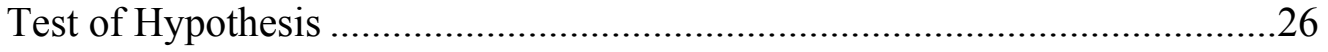

Ethnicity on Body Objectification ............................................................2

Type of Surgery on Body Objectification......................................................28

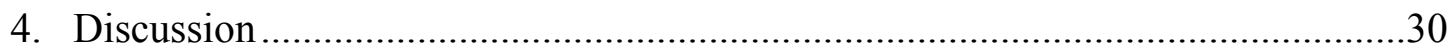

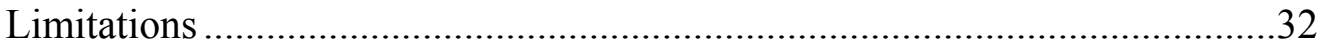

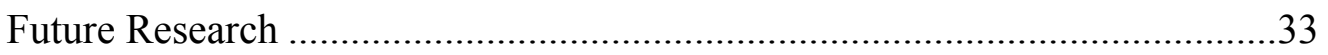




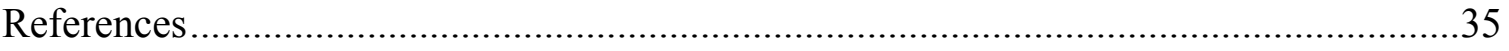

Appendices

A. Informed Consent Form 


\section{TABLES}

Tables

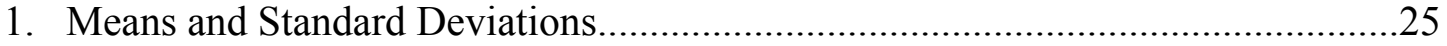

2. Correlations Matrix of Variables and Controls......................................................26

3. Effects of Ethnicity and Type of Surgery on Body Objectification

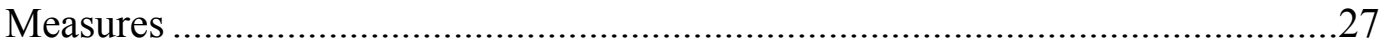

4. Effects of Ethnicity and Surgery (yes/no) on Body Objectification

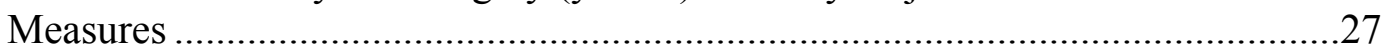




\begin{abstract}
OF THE THESIS
Body Objectification and Elective Cosmetic Procedures in African American Women by

\author{
Allycin Powell-Hicks \\ Doctor of Philosophy, Graduate Program in Psychology \\ Loma Linda University, March 2011 \\ Dr. Gloria Cowan, Chairperson
}

Trends in cosmetic surgery are an ever-popular topic of discussion, however, little psychological or empirical research has been devoted to understanding specific psychological factors for ethnic minorities. African American women have historically fallen outside of Euro-centric beauty norms and have been subjected to objectification in media and interpersonal interactions. First, this study investigated the differences between African American women and Caucasian women on three dimensions of body objectification. Body objectification was assessed through three subscales of the Objectified Consciousness Scale: 1) body surveillance, 2) Shame about appearance, and 3) a women's assessment of control of her personal appearance. African American women were expected to exhibit higher scores on Control and lower scores on Shame and Surveillance than Caucasian women. Secondly, objectification scores were expected to differ among two self-selected cosmetic conditions and the Body Control. Cosmetic surgery was broken into three mutually exclusive groups: 1) women who received an invasive cosmetic procedure, 2) minimally invasive cosmetic procedure, or 3) no procedure control group. Women are hypothesized to endorse higher scores on Control, Surveillance, and Shame if they had undergone an invasive cosmetic procedure rather than women who elected for noninvasive procedures. Both invasive and noninvasive 
cosmetic groups were thought to score higher than the control group. Lastly, this study explored the possible differences between African American and Caucasian women and their choices in body enhancement procedures in predicting body objectification. Body mass index and income were held constant. Women were sampled from cosmetic surgeons' offices, hair salons, local gyms, and a local women's meeting and administered the Objectified Body scale. Forty-one African American women and 23 Caucasian women were recruited. None of the hypothesis were supported in this study; however, when the surgery variable was dichotomized, those who had surgery and those who did not, two of the three hypothesis were supported. Hypothesis one was supported, with African American women experiencing higher Body Control than Caucasian women. Hypothesis two was also supported. Women who had any cosmetic procedure endorsed higher Surveillance than women who had no procedure. 


\section{Chapter 1}

\section{Introduction}

Each night Pecola prayed for blue eyes. In her eleven years, no one had ever noticed Pecola. But with blue eyes, she thought, everything would be different. She would be so pretty that her parents would stop fighting. Her father would stop drinking. Her brother would stop running away. If only she could be beautiful. If only people would look at her.

Toni Morrison

The Bluest Eye

In the United Stated and other industrialized countries, individual beauty is indicative of social status, intelligence, trustworthiness, and desirability. Euro-centric beauty ideals can be detrimental to those who fall outside of these norms. Thus, the present study was designed to examine the relationship between ethnicity and cosmetic procedure decisions and body objectification among women. Why is beauty an important construct in society? What assumptions does beauty generate about an individual? Body objectification seeks to explain the social phenomena embedded within women's internalization of cultural norms about their bodies, body shame, and the control women believe they exert over their appearance. According to this construct, beauty and physical appearance are used by the dominant culture, Euro-American males, to either "seduce" or "reject" women.

\section{Background}

Beauty is an important construct in many, if not all, populations and cultures. Many may be reluctant to admit the importance of beauty in society; however, a woman's 
beauty may indicate many things about her, including social status (Backman \& Adams, 1991), reproductive desirability (Sarwer, Magee, \& Clark, 2004), income (Hamermesh \& Biddle, 1994), intelligence (Langlois et al., 2000), or even the likelihood she may receive help from passers by (Cunningham, 1987). It's been found that attractive people are typically attributed more positive personality characteristics leading to preferential treatment (Sarwer, Magee, \& Clark, 2004). This attribution is also referred to as the "beauty is good" principle, which states that people and communities attribute positive attributes on individuals who are deemed attractive while placing negative traits on unattractive individuals (Langlois et al, 2000).

Preferential treatment of the attractive permeates our culture, and two differing perspectives are used to explain this phenomenon. One perspective, natural selection, emphasizes the influence of evolution on contemporary beauty perception, whereas the other emphasis society and culture's impact on the perception of beauty. The evolutionary perspective places emphasis on mate selection and fitness-related evolutionary theories (Langlois et al., 2000). In contrast, social expectancy theories and societal perspectives fall within two basic assumptions a) cultural norms affect the behaviors of targets and perceivers, and b) socially constructed stereotypes form their own reality (Langlois et al., 2000). The perspectives of these theories may appear to be conflicting; however, one conclusion emerges; beauty and physical appearance are of consequence in our society.

With beauty so firmly placed in the American psyche, African American women may find it difficult to transcend these socially constructed and endorsed views. This theme has been reiterated constantly throughout western culture with adages such as: 
Beauty is the promise of happiness (Marie-Henri Beyle/Stendhal), and conversely, Beauty is in the eye of the beholder, Never judge a book by its cover, and Beauty is only skindeep (Langlois et al., 2000). These deeply held beauty beliefs are reinforced through social interactions daily. It has already been established that beauty is an important construct in most societies. How then do African American women view themselves while living in a society that does not deem them beautiful?

While taking into account the perspectives attempting to interpret beauty, this study will investigate the relationship ethnicity (African American or Caucasian) and the choice to obtain a cosmetic procedure (invasive procedure, minimally invasive procedure, or no procedure) maintain with the three dimensions of Body objectification: 1) Body Surveillance, 2) Shame about appearance, and 3) a women's assessment of control of her personal appearance. First, this study will investigate the differences between African American women and Caucasian women on three dimensions of body objectification. African American women were expected to exhibit higher scores on Control and lower scores on Shame and Surveillance than Caucasian women. Secondly, objectification scores were expected to differ among two self-selected cosmetic conditions and the control. Women are hypothesized to endorse higher scores on control, surveillance, and Shame if they had undergone an invasive cosmetic procedure rather than women who elected for noninvasive procedures. Both invasive and noninvasive cosmetic groups were thought to score higher than the control group. Lastly, this study explored the possible differences between African American and Caucasian women and their choices in body enhancement procedures in predicting body objectification. 


\section{Evolutionary Theory/Natural Selection}

Evolutionary theory, originally postulated by Charles Darwin, is centered on the premise that reproduction is the primary goal for all species (as cited in Sarwer et al, 2003). Therefore, when explaining beauty perception through this perspective, contemporary beauty standards stem from the mating habits of our ancestors, which lead to current selection practices (Gangestad \& Scheyd, 2005). Males and females of a species select mates using different criteria. For example, in most animals males attract females with beautiful plumage or grand gestures whereas in humans the responsibility of attracting a mate through physical beauty falls on the female rather than on the male. Therefore, according to evolutionary principles, males choose physically attractive females due to perceived reproductive fitness (Buss, 1998; Langois et al, 2000). Reproductive fitness is historically grounded in five primary indicators of beauty: youthfulness, pathogen resistance, symmetry, body ratios, and averageness (Sarwer et. al, 2004).

According to Symons (1979) a youthful appearance has often been linked to reproductive potential or attractiveness (cited in Sarwer et al. 2004), and as women age they are rated as appearing less feminine (Zebrowitz, Olson, \& Hoffman, 1993). Conversely, men retain masculinity ratings irrespective of age (Deutsch, Zalenski, \& Clark, 2002). Pathogen resistance is another indicator of physical attractiveness. Statistical evidence does not support an actual link between physical attractiveness and pathogen resistance (Sarwer et al. 2004); however, pathogen resistance has been noted to indicate reproductive potential (cited in Sarwer et al 2004). This attraction toward individuals that appear pathogen resistant is more prevalent in countries where there is a 
high pathogen risk than in a country where there is a lower pathogen risk (Ganesta \& Buss, 1993). Individuals possessing bilateral symmetry, which is the property of being divisible into symmetrical halves on a unique plane, are assumed because of the symmetry to be pathogen resistant (Thornhill, Gangestad, 1993). Thus, they are seen as more physically attractive. It has been found that bilaterally symmetrical men become sexually active younger and have more sexual experiences than men who are not as bilaterally symmetrical (Thornhill, Gangestad, 1994). Waist-to-hip ratio (WHR), as explained by Sarwer et al. 2004, is "the distribution of fat between the upper and lower body relative to the amount of abdominal fat" ( $p$ 30). WHR is another indicator of physical beauty, where women with WHRs lower than 0.8 are believed to be more attractive, younger, healthier, and appear more feminine (Singh, 1993).

The final indicator of physical attractiveness as postulated by natural selection theory is averageness of appearance. According to a study performed by Langlois and Roggman (1990) when a number of different faces were placed in a computer program and combined to create an average, these faces were rated on their attractiveness. The female and male facial composites were rated significantly more attractive than the individual faces (Langlois \& Roggman, 1990). According to Sarwer et al. (2004) the "ideal composite female face" had a full but "smaller than average mouth" while the face remained "petite" with a small jaw line, and "pronounced eyes and cheekbones" (p 30).

\section{Socio-Cultural Theories of Beauty}

Evolutionary theory, being primarily deterministic, does not give much room for changes in socio-cultural attitudes surrounding beauty (Fredrickson \& Roberts, 1997). Evolution is a force theorized to be constant, but social factors such as media influences 
and male subjugation of women can be altered over time, altering our perception of beauty (Adamson, 2006). "Beauty is subject to hegemonic standards of the ruling class... and definitions of beauty vary among cultures and historical periods" (Patton, 2006, p. 25). Shifts in beauty ideals can be seen in the American culture even in the last century. In the early twentieth century when beauty was defined by the layered hairstyles and gracile (slender and thin especially in a charming or attractive way) features of the Gibson girl, feminine beauty was ideal. Cultural beauty then shifted to the boyish figure of the flapper girls of the 1920s and 1930s. Then came the curvaceous womanly figure of the 1950s with beauty icons like Marilyn Monroe, whose size twelve physique is taboo today. The 1970s introduced an extremely thin aesthetic embodied by the British model Twiggy. These beauty ideals surrounding the long and lean have persisted until today. There have been obvious changes in beauty perception, thus illuminating the influence of socio-cultural principles on the opinions about beauty. This assumption does not negate the role of evolutionary theory in beauty perception but allows room for culture. In our culture beauty is pertinent throughout the lifespan beginning in infanthood and extending into adulthood.

Childhood. Society is a classroom that establishes social norms via social learning and expectancy theories. This education begins from birth and extends into adulthood. Most children in the United States share common memories of being read Cinderella and Snow White; however, they fail to realize the virtues they are being taught about beauty. One study performed by Baker-Sperry and Grauerholz (2003) found that $94 \%$ of fairy tales mentioned physical appearance. In each story physical appearance was mentioned an average of 13.6 times, with the appearance of women being mentioned 
almost three times more than that of men. It was also found that in many stories beauty was rewarded whereas the lack thereof was punished. Also the tales with the most beauty-laden references were heavily reproduced and made into feature films, such as Cinderella, Snow White, and Briar Rose (Sleeping Beauty). In all of these stories the beauty of young women was valued over beauty in older women, and these beautiful young women were often subjected to jealousy and malice (Baker-Sperry \& Grauerholz, 2003). Thus it can be seen that the beauty is good principle postulated by Langlois is imprinted even in childhood (2000).

Transcending stories and fairy tales, children experience differential treatment from other children and adults based on their attractiveness as well as being able to perceive beauty in others themselves. For example, infants seen as attractive by adults are seen as happier, smarter, and more pleasant (Stephan \& Langlois, 1984). Also the differential parental solicitude theory contends that parents put more effort into offspring who exhibit more quality. Thus, if attractiveness is an indicator of quality, more rearing effort is provided to attractive children rather than unattractive children (Barden, Ford, Jensen, Rogers-Salyer, \& Salyer, 1989). Favoring the attractive also extends into the classroom, where attractive students are perceived by educators as more popular, confident, intelligent, having better social skills (Sarwer, Magee, \& Clark, 2004), and more academically developed, competent, adjusted and possessing more social appeal (Langlois et al., 2000). It has even been found that among 8-year-olds, physical attractiveness and academic competence predict $53 \%$ of the variance in self-esteem. By age $11,43 \%$ of the variance is attributed only to physical attractiveness (Muldoon, 2000). It has also been found that infants as young as three months old can discriminate between 
attractive and unattractive faces, with more attention being given to attractive ones (Langlois, Roggman, Casey, Ritter, Rieser-Danner, \& Jenkins, 1987). The influence of beauty and attractiveness is established in childhood by parents, educators, other adults, and peers. Beauty is then further reinforced in adulthood.

Adulthood. Favorable treatment of the attractive then continues in adulthood where beauty is valued in the work place and interpersonal relationships. Attractive individuals receive more job offers than unattractive applicants; this is predominantly true in the hiring of women (Sarwer, Magee, \& Clark, 2004). This trend is seen consistently in experienced and inexperienced managers (Marlowe, Schneider, and Nelson, 1996). As in to evolutionary theory, physical attraction plays a large role in establishing romantic relationships, where attractive people are able to secure more desirable partners (Gangestad \& Scheyd, 2005). Men have been found to place more emphasis on physical attractiveness in relationships than women (Buss, Shackleford, and Kirkpatrick, 2001; Feingold, 1990). Freedman (1986) addressed this masculine emphasis on beauty, and found that in general women expend great energy to achieve beauty in order to establish relationships. Many cultures place particular value on beauty when selecting a partner. According to Buss (1989), from among 37 cultures, people in the United States only placed slightly more value on beauty than those in other cultures.

\section{Body Objectification}

Objectified body consciousness, then, creates a situation in which a woman has a contradictory relationship to her body. On the one hand, we have seen behaviors such as loving the self through surveillance, "choosing" cultural body standards, and acquiring appearance controlling skills can appear to be positive, empowering experiences for women, on the other hand, each of these behaviors also has negative consequences for how a woman feels about her body and about herself. Without an understanding of $\mathrm{OBC}$, we cannot fully understand women's complex 
and contradictory feelings toward their bodies, nor can we begin to speculate on how negative body experience can be changed.

(McKinley \& Hyde, 1996; p. 185 -186)

Socio-cultural expectations of beauty can be further explored using objectification theory. Objectification explains how cultural norms can affect internal representations of self, therefore elucidating how society's beauty expectations can internally affect women's perceptions of beauty and their bodies. According to Fredrickson and Roberts (1997) "the common thread running through all forms of sexual objectification is the experience of being treated as a body (or collection of body parts) valued predominantly for its use to (or consumption by) others" (p. 174). Bartky (1990) also commented on society's role in dismembering women into body parts rather than seeing them as complete figures, a component of Body objectification theory. The most profound implication of society's objectification of women is the internalization of these external views (Fredrickson \& Roberts, 1997). When women begin to internalize society's view, they begin to look at themselves as objects and these views become integrated into their sense of self (Fredrickson \& Roberts, 1997). When women feel as if they "come up short" in comparison to society's ideals, a sense of shame develops (Lewis, 1992). In all actuality, only 1 in 40,000 women posses the size and shape needed to be a model (Fredrickson \& Roberts, 1997). The internalization of these social constructs can be harmful, but can also provide women with a vehicle of power when they meet society's beauty standards (Unger, 1979). As mentioned earlier, physical attractiveness can offer women positive social roles, thus guaranteeing them increased social mobility (Unger, 1979). 
In 1996 McKinley and Hyde constructed The Objectified Body Consciousness Scale. This scale focused on three key features of body objectification: Body Surveillance, Body Shame which includes the internalization of cultural standards, and a sense of Control women feel over their bodies and appearance (Mckinley \& Hyde, 1996).

First, Body Surveillance, explains the process by which women view their bodies as others view them (McKinley, 2006). While surveilling their bodies women begin to view themselves as foreign entities (Fredrickson \& Roberts, 1997). As women survey their bodies, they begin to focus on the perceptions society holds about their appearance, and they may experience subsequent concern about falling short of societal standards. During surveillance women feel as if they should comply with societal standards in order to avoid judgment for falling short of norms (McKinley \& Hyde, 1996). This process serves to decrease the discrepancy between society's expectations and expectations imposed by self. Surveillance can serve is a positive capacity encouraging self-love, health, and individual achievement (McKinley \& Hyde, 1996; Spitzack, 1990), whereas it is negatively expressed when women internalize feelings of inadequacy (Carver \& Scheier, 1981; McKinley \& Hyde, 1996). Women who constantly survey themselves are more susceptible to the influence of others (McKinley \& Hyde, 1996). Internalizing external views and deeming that one has come up short of societal standards will inevitably lead to shame about one's own body. Constanzo (1992) argues a linear pathway to shame where women initially comply with an innocuous conforming pressure, followed by identification with the societal information, concluding in an incorporation of the once foreign societal standard into the self. The internalization of societal norms creates a sense that external standards are actually self-originated which 
creates the perception that achieving beauty norms or the lack there of is a personal choice (McKinley \& Hyde, 1996). Shame goes beyond body esteem and permeates a woman's global self-representation and her inherent goodness. However, shame can be counteracted by feelings of control over their appearance. The assumption of control over appearance provides women with the motivation to strive toward beauty norms and to view these norms as reachable (Wolf, 1991). Bartky (1988) found that giving women a feeling of control over their physical appearance provides a sense of psychological even physiological well-being. Achieving the beauty norm can cause stress in women; thus, feelings of control can mitigate the stress by providing the psychological strength necessary (McKinley \& Hyde, 1996). Control, though mostly positive, may lead to restricted eating which can lead to disordered eating in some women (McKinley \& Hyde, 1996).

Body objectification affects women of diverse ethnic backgrounds differently. Hurtado (1989) postulated that Objectification affects Caucasian women and African American women in distinctive capacities. In a culture dominated by Caucasian males (Fredrickson \& Roberts, 1997), Caucasian women are oppressed through "seduction" whereas Women of Color are oppressed through "rejection." The difference in Objectification between Caucasian women and Women of Color is also present in popular media sources. African American women are most often portrayed in an ethnically stereotypical manner. They are depicted as animalistic (Fredrickson \& Roberts, 1997), sexual, dominant, masculine, and primary focus is placed on their bodies rather than on their facial features (Fredrickson \& Roberts, 1997, Zuckermn \& Kieffer, 1994). The differences in the method of objectification between Caucasian women and 
Women of Color may point to further differences in these two groups' experience and internalization of Objectification. This may also help to explain beauty research needs to promote ethnically diverse samples. Many studies are performed on Caucasian women and the results are simply generalized to Women of Color (Zinn, 1990).

\section{African American Women}

The Black woman had not failed to be aware of America's standard of beauty nor the fact that she was not included in it; television and motion pictures had made this information very available to her. She watched as America expanded its ideal to include Irish, Italian, Jewish, even Oriental and Indian women. America had room among its beauty contestants for buxom Mae West, the bug eyes of Bette Davis, the masculinity of Joan Crawford, but the Black woman was only allowed entry if her hair was straight, her skin light, and her features European; in other words, if she was as nearly indistinguishable from a Euro-American woman as possible. (Wallace, 1979, p. 157)

Throughout United States history, African American beauty has been underappreciated and "disparaged" (Patton 2006, p. 26). The North American beauty standard is focused on Caucasian beauty, which is mostly unattainable to many African American women. Consequently, out of necessity the African American community fashioned its own standards of beauty. This standard exists within the larger Caucasian culture, and emphasizes some standards inconsistent with Caucasian beauty standards and others that strive to emulate it. The African American community places value on personality, hair texture, facial features, and prefers heavier bodies (Breitkopf, Littleton, \& Brenson, 2007; Boyd-Franklin, 1991). For example, Caucasian women typically maintain a "uniform" perception of beauty and adhere closely to social beauty norms (Wolf, 1991). Conversely, African American women perceive beauty in less uniform terms, incorporating personality traits as well a physical ones (Parker et al.,1995). 
African American women also tend to define themselves in androgynous terms and it has been seen that women who do not constrain themselves to strict feminine terms maintain higher body esteem (Harris, 1994).

Esteem in the African American community transcends even beyond body type, where hair has been described as a woman's crowning glory, her most attractive feature. Hair holds particular importance and has been distilled into two mutually exclusive categories; "good hair" and "bad hair." "Good hair" is easy to manage and closely resembles European textured hair. Whereas, "bad hair" is tightly coiled, more difficult to manage, and intrinsically does not resemble European hair texture. Hall (1995) addresses the association of "goodness" with the globalized individual, far transcending just hair texture. In short, "good hair" equals good person.

Globalized goodness also extends to other realms of beauty measurement, such as facial features, and body types. The Euro-American beauty standard value thinner lips and generally narrow facial features. Negative feelings may emerge in communities who fall outside of these beauty norms, in particular African Americans (Hall, 1995). On average African American women possess a higher body weight than Caucasian women, though African American women's weight perception is not associated with low body satisfaction whereas Caucasian women's perceptions are (Thomas, 1989). This "fluid" concept of beauty may lead to the acceptance of beauty norms that differ from those offered by the dominant culture. Historically, African Americans have been required to make changes to their appearance to blend with the Euro-American beauty norm. For example, during slavery adopting Euro-American beauty standards was conducive for survival and upward mobility; thus, Black women strove to emulate beauty as expressed 
by Euro-American women. African American women who appeared Euro-American were allowed to work in the master's house avoiding hard labor, providing access to education, and the possibility of freedom (Patton, 2006).

This reality has lead to a social phenomena coined by Jones and Shorter-Gooden (2003) as "The Lily Complex. “ "The Lily Complex" describes a state where African American women attempt to "cover" or disguise their ethnic features in order to be seen as acceptable to the mainstream Caucasian beauty standard. -This systematic covering has helped to marginalize the beauty in the African American community. “...As Black women deal with the constant pressure to meet a beauty standard that is inauthentic and often unattainable, the lily complex can set in" (Jones \& Shorter-Gooden, 2003, p 177). However, this drive to attain a beauty ideal not of her own can lead an African American women to loath her own beauty and to feel "Black is not Beautiful" (Patton, 2006).

As stated earlier, beauty standards are established by the dominant culture, which may cause negative self-image in minorities embedded within that culture (Fredrickson \& Roberts, 1997). This trend can be seen regarding beauty norms and may partially explain why objectification affects women of color differently than Caucasian women. However, most studies concerning objectification, self-esteem, and general body issues among African American women suggest that African American women do not hold themselves to Caucasian standards of beauty (Frisby, 2004; Evans \& McConnell, 2003; Crocker \& Major, 1989). Crocker and Major (1989) in particular stated that members of stigmatized groups compare themselves to others from within the same stigmatized group rather than the dominant culture. For example a study by Frisby (2004) found that African American women shown pictures of attractive Caucasian female models did not express lowered 
self-evaluations. However, African American women with pre-existing low selfsatisfaction experienced decreased self-evaluations when shown pictures of attractive African American models.

Historically, African American women have been seen as being protected against internalizing societal norms where slender body types are preferred (Breitkopf, Littleton, \& Berenson, 2007). The "buffering" provided in the African American culture serves to protect African American women from stigmatization and a non-inclusive beauty norm (Molloy \& Herzberger, 1998). Diminishing differences are found between Caucasian and African American women when income and education are held constant, possibly indicating difference lies socioeconomic class rather than differences actually attributed to cultural differences (Breitkopf, Littleton, and Berenson, 2007; Radecki et al., 2007). Thus, social class differences may account for differences between Caucasian and African American women. Most present studies are composed of primarily Caucasian women and the African American women sampled are often of low socioeconomic status. Therefore, obtaining samples of African American women with similar education and income levels may reduce the differences between Black and Caucasian women. In the present study, education and income will be held constant.

Women of Color have been excluded from samples; hence, results found have been based on Caucasian samples and generalized to women of color (Zinn, 1990). This pattern implies a general uniformity in the conceptualization of beauty among ethnic groups. However, according to Poran ( 2002, p. 79), "Beauty must be reconceptualized as a raced experience in order to understand and explore fully the diverse experiences women have in relation to, and within, cultures. Previous assumptions of the uniform 
standard of beauty must be reconceived because although the standard may be uniform, perceptions of, and responses to it are not." There are obviously differences in the way African American and Caucasian women perceive and experience beauty. Thus, the inclusion of African American women in research is vital to ensure a proper investigation of this phenomenon.

If the research is correct in asserting that African American women are buffered from external beauty standards then why are African Americans increasingly receiving elective cosmetic procedures? Hall (1995) addressed this when she alluded to the multidimensionality of this dilemma. African American women are often struck with feelings of self-abasement and pain regarding their brand of beauty. For many African American women feelings of shame and disgust begin in adolescence and continue well into adulthood. This study will investigate the differences in objectification scores between African American and Caucasian women. Considering the African American insulation from external beauty norms, in group comparisons, and acceptance of a range of beauty norms African American women are expected to exhibit higher feelings of control of their appearance, and less surveillance and shame of self. This may explain the how being an African American woman affects Body objectification.

\section{Cosmetic Surgery}

Across various cultures women's bodies have been objectified requiring women to conform to indigenous beauty standards (Patton, 2006). This conformity has resulted in phenomena such as foot binding in China (Patton, 2006), corset wearing and waist synching in Europe, neck lengthening in parts of Asia as well as Africa, and a number of other physically debilitating practices in the search of beauty. Today, in the United States 
as well as other countries, objectification affects women from diverse ethnic backgrounds, sometimes being a powerful motivator for modifying beauty. Cosmetic surgery is often seen as a means by which women are able to alter their appearance in order to attain an otherwise unachievable beauty ideal.

African American women are not exempt from this desire to modify their appearance. In a statement released by the president of the American Society of Plastic Surgeons (ASPS), Bruce Cunningham (2006), he stated "We are seeing a significant increase in the number of cosmetic plastic surgery procedures across all ethnic groups...The increase can be, in large part, attributed to greater exposure to the benefits of plastic surgery, a growing acceptance of the specialty, and increased economic power within these ethnic groups" (p. 1).

Overall there has been an increase in cosmetic surgery and procedures performed in the United States since 1992. Between 1992 and 2005 there was an increase of $775 \%$ in all cosmetic procedures, with cosmetic surgical procedures increasing by $266 \%$ and minimally invasive procedures increasing by $3158 \%$ (American Society of Plastic Surgeons, 2005). Men accounted for $9 \%$ of cosmetic procedures, leaving the other $91 \%$ women (American Society of Plastic Surgeons, 2005). Increasing trends of elective cosmetic procedures are evident in minority populations as well, where people of color account for over $20 \%$ of the procedures performed (Board Certified Plastic Surgeon Resource, 2005). Hispanics received 921,000 procedures in 2005, which is an increase of 67\% since 2004, African Americans received 769,000 procedures which has also increased by 67\% since 2004, and Asians received 437,000 procedures in 2005 which was an increase of 58\% between 2005 and 2004 (Board Certified Plastic Surgeon 
Resource, 2005; American Society of Plastic Surgeons, 2006). African Americans alone made up $8 \%$ of cosmetic surgery patients in 2005 (ASPS, March 2006). The top three cosmetic procedures in this population were nose reshaping, liposuction, and breast reductions (Board Certified Plastic Surgeon Resource, 2005). This increase in cosmetic procedures has helped raise questions about ethnic minorities and in particular women of color and the role beauty standards play in their lives.

What conclusions can be made concerning the pursuit of beauty in our culture? Do we place as much emphasis on beauty as research suggests? Considering the large increase in cosmetic medical procedures, can we assume that women will go the distance to achieve a physical appearance they deem will help them achieve greater social mobility? Sarwer et al (2004) concluded that "Perhaps the research has confirmed what people who seek cosmetic procedures have suspected-That if they are more physically attractive, they will be seen and treated more positively...The possibility of improved social and professional interactions may motivate many people to seek cosmetic treatments" (Sarwer et al., 2004, p. 35).

This study investigated the role ethnicity and cosmetic procedure choice play in determining women's scores on Body objectification. Firstly, this study investigates how ethnicity (Caucasian or African American) affects scores on Body objectification. Secondly, It examined the differences among women who received invasive cosmetic procedures, minimally invasive cosmetic procedures, or no cosmetic procedures (control group) on their levels of Body objectification; Control, Shame, and Surveillance. Finally, the effects of ethnicity within each cosmetic condition and body objectification will be 
assessed; that is, the interaction of ethnicity and cosmetic condition on body objectification will be explored.

First, this study will investigate the differences between African American women and Caucasian women on three dimensions of body objectification. African American women were expected to exhibit higher scores on Control and lower scores on Shame and Surveillance than Caucasian women. Secondly, objectification scores were expected to differ among two self-selected cosmetic conditions and the control. Women were hypothesized to endorse higher scores on control, surveillance, and Shame if they had undergone an invasive cosmetic procedure rather than women who elected for noninvasive procedures. Both invasive and noninvasive cosmetic groups were thought to score higher than the control group. Lastly, this study explored the possible differences between African American and Caucasian women and their choices in body enhancement procedures in predicting body objectification. 


\section{Chapter 2}

\section{Method}

This chapter addresses demographic information and locations where participants were recruited. Measures will be addressed as well as calculations, questionnaire dissemination, collection and how the analysis will be run.

\section{Participants}

64 women were recruited from 1 fitness center, 1 beauty parlor, a local women's meeting, and 3 cosmetic surgeon offices; 2 private practices located in Orange county, and 1 teaching institution in San Bernardino County. The sample consisted of 41 African American and 23 Caucasian women. Women ranged in age from 20 to 84 with a mean age of 44 years and a standard deviation of 15, with the average age of African Americans being 44.59 and Caucasians 43.35.

\section{Measures}

The Objectified Body Consciousness scale constructed by Nita M. McKinley and Janet S. Hyde (1996) is a 7-point Likert scale ranging from strongly disagree to strongly agree, with a middle point of neither agree or disagree. Subjects can also circle NA if the item does not apply to them. The Objectified Boy Consciousness scale consisted of three subscales: Surveillance Scale, Body Shame Scale, and Control Beliefs Scale, with alphas of; .89, .75, and .72 respectively (McKinley \& Hyde, 1996). The alphas found in this study were .59 .62 , and .60 respectively and lower than the alphas found in the McKinley \& Hyde article. Each subscale has 8 items. Surveillance addresses women's appraisals 
of their appearance based on the opinions of those in society and the tendency to assess their inherent shortcomings. Higher endorsements indicate higher levels of surveillance. An example is "I often worry about whether the clothes I m wearing make me look good." The Body Shame Scale measures a women's shame associated with her physical appearance. A sample item is "When I ' $m$ not the size I think I should be I feel ashamed." The higher the endorsement on items, the higher the level of body shame Finally, the Control Beliefs Scale measures the degree to which a woman views the control she holds over her appearance. An example of a control it is "I think a person can look pretty much how they want to if they are willing to work at it."

Ethnicity was based on self-reported personal ethnic identification as well as that of their parents. There were no mixed race participants that self-identified as mixed or other. Subjects reported their weight (lbs) and height (in) which was converted into a Body Mass Index (BMI). BMI was obtained via a mathematical calculation of weight and height. The Imperial BMI calculations are the participant's weight in pounds multiplied by 703, divided by the participants height in inches squared (Hedley, et al, 2004). Estimates of underweight is a BMI of less than 18.5 , normal weight is between 18.5 and 24.9 , overweight is $25-29.9$, and obesity is a BMI of 30 or greater (Hedley, et al, 2004). BMI was treated as a continuous variable.

$$
\frac{\text { Weight }(\mathrm{lbs}) * 703}{{\text { Height }(\text { in })^{2}}^{2}}
$$

\section{Procedure}

Participants were given questionnaires at fitness centers, beauty parlors, and cosmetic surgeons' offices. The questionnaire took approximately 20 minutes to 
complete and was either returned to the receptacle in which it was received, or via mail to the researcher. Questionnaires were collected weekly or monthly according to the volume of surveys completed.

\section{Data Analysis}

Correlations were used to assess the relationship among variables. A 2-way MANOVA was performed with ethnicity (African American and Caucasian) and cosmetic group membership (invasive, minimally invasive, and control) as the IVs; in a second MANOVA surgery is broken into two mutually exclusive groups; women who have undergone any cosmetic procedure (either invasive or minimally invasive) and women in the control group, also treated as IVs. Both MANOVAs utilize Body objectification (Surveillance, Body Shame, and Control) as the DVs. Body Mass Index (BMI) and income were held constant to control their effects on statistical outcomes. univariate analysis for the three OBC subscales followed the MANOVA. 


\section{Chapter 3}

\section{Results}

In this chapter I will present the preliminary analysis and demographic data, followed by the multivariate analysis testing the hypotheses.

\section{Preliminary Analysis}

Table 1 presents means and Standard Deviations for dependent and control variables. The income variable was broken into four categories, $\$ 10,000$ or less, $\$ 10,000-\$ 50,000, \$ 50,000-\$ 100,000$, and $\$ 100,000$ and up. The average household income for the sample was 2.81 , which indicates an income falling at the upper end of the $\$ 10,000-\$ 50,000$ range. Caucasian women fell between $\$ 10,000$ and $\$ 50,000$ with African Americans' income falling between $\$ 50,000$ and $\$ 100,000$. African American women scored significantly higher than Caucasian women on measures of income, $t(63)=2.29, p=.03(\bar{x}=3.02$ and $\bar{x}=2.43$ respectively $)$. Education was broken into six levels, "elementary/middle school” (1), "some high school” (2), "completed high school" (3), "some college" (4), "completed college" (5), and "graduate or professional school"

(6). African Americans in the sample reported an average score of 5.39. Similarity Caucasians endorsed a mean score of 5. Both groups had averages of "completed college." There were no significant mean differences between African Americans and Caucasians on education, $t(62)=1.58, p=.12$. BMI was also a control variable and there was no difference seen between African American and Caucasian participants BMI, $t(62)$ $=.15, p=.88$. 
Participants fit into one of three mutually exclusive groups: those who have received an invasive cosmetic procedure (16 women, $25 \%$ ), 50\% of which were African American and 50\% were Caucasian; those who have received minimally invasive cosmetic procedure (13 women, 20.3\%), 69.2\% of which were African American and $30.8 \%$ were Caucasian women; or those who have never had an elective cosmetic procedure (35 women, 54.7\%) 68.6\% African American and 31.4\% Caucasian. Each group was to have ideally consisted of 65 participants according to Cohen (1992), but these numbers were not achieved in this study.

Of women who had any procedure, $8.3 \%$ of Caucasian women reported facelifts with another $8.3 \%$ reporting chemical peels and microdermabrasion. Whereas, $5.9 \%$ of African American women reported facelifts while 29.4\% reported chemical peels and microdermabrasion. Surgeries of the body included breast augmentations and breast reductions. Forty-one percent of Caucasian women admitted to breast augmentations where there were no African American women in the study who underwent a breast augmentation. However, 5.9\% of African Americans reported breast reductions. Twenty-five percent of Caucasians reported liposuction of either the arms or abdomen where, $23.5 \%$ of African Americans reported liposuction. Tummy tucks were more popular among African Americans with 8.3\% of Caucasians endorsing the procedure as compared to $17.6 \%$ of African Americans. 
Table 1

Means and Standard Deviations

\begin{tabular}{llll}
\hline Group & N & M & SD \\
\hline Surveillance & 64 & 3.81 & .91 \\
Shame & 64 & 2.77 & .88 \\
Control & 64 & 4.45 & .73 \\
$\quad$ African American & 41 & 4.62 & .71 \\
Caucasian & 23 & 4.14 & .67 \\
BMI & 64 & 26.43 & 5.41 \\
Income & 64 & 2.81 & 1.02 \\
Education & 64 & 5.25 & .96 \\
\hline
\end{tabular}

Table 2 presents Pearson correlations of control variables and Body objectification subscales, which revealed three significant moderate sized correlations. There was a significant correlation between BMI and Shame $(\mathrm{r}=.34, p<.01)$ indicating that as BMI increased, an individual's endorsements of Shame also increased. Income was positively correlated with control $(\mathrm{r}=.37, p<.01)$; individuals who reported higher income expressed increased perceptions of Body Control.

Regarding intercorrelations among the OBC subscales, there was a significant correlation between Surveillance and Shame $(r=.40, p<.01)$, indicating that higher endorsements of Surveillance indicated higher feelings of shame about their bodies (see Table 2). McKinley and Hyde (1996) also found a strong significant correlation $(r=.66)$ between Surveillance and Shame. They also found a significant positive correlation of $(r=.23)$ between Shame and Body Control (McKinley and Hyde, 1996), whereas in this study no significance was observed $(r=-.20, p=.11)$. No significant correlation was seen between Body Control and Surveillance $(r=.23, p=.06)$. Thus, Surveillance and Shame shared a significant amount of variance whereas Body Control did not appear to maintain a relationship. 
Table 2

Correlations Matrix of Variables and Controls

\begin{tabular}{lccccc}
\hline Measure & Surveillance & Shame & Control & BMI & Income \\
\hline Surveillance & 1 & $.40^{*}$ & .23 & .01 & -.11 \\
Shame & & 1 & -.20 & $.34^{*}$ & -.25 \\
Control & & & 1 & -.02 & $.37^{*}$ \\
BMI & & & & 1 & -.12 \\
Income & & & & & 1 \\
\hline
\end{tabular}

Note: $* \mathrm{p}<0.01$

\section{Test of Hypothesis}

To test for ethnicity and type of procedure effects on body objectification, a 2 x 3 Multivariate Analysis of Variance (MANOVA) was conducted. Because sample size was limited, in addition to the originally planned three-way cosmetic condition, the two surgery conditions were combined for an additional analysis. Thus, two separate MANOVAs were conducted, one with three levels of cosmetic surgery (invasive, minimally invasive, and control), found in Table 3, and the second with cosmetic surgery split into two groups (surgical procedure and no surgical procedure), found in Table 4. Family-wise Error Rate was set at $p<0.05$ level. BMI and income were included in the final analyses as controls. Education was not included because it was not related to either ethnic or surgery group or to the OBC measure. 
Table 3

Effects of Ethnicity and Type of Surgery on Body Objectification Measures

\section{Multivariate Univariate Fs}

\begin{tabular}{lccccc}
\hline Source & $\boldsymbol{d} \boldsymbol{f}$ & $\mathbf{F}$ & Surveillance & Shame & Control \\
\hline Ethnicity & 3 & 2.35 & 1.64 & .61 & 3.65 \\
Type of Surgery & 3 & .97 & 2.36 & .32 & .39 \\
BMI & 3 & 2.58 & .37 & $6.74^{*}$ & .10 \\
Income & 3 & $2.70^{*}$ & 1.61 & 2.06 & $5.17^{*}$ \\
E x S & 3 & .68 & 1.14 & .12 & .34 \\
\hline
\end{tabular}

Note: ${ }^{*} p<0.01$

Table 4

Effects of Ethnicity and Surgery (yes/no) on Body Objectification Measures

Multivariate Univariate Fs

\begin{tabular}{lccccc}
\hline Source & $\boldsymbol{d} \boldsymbol{f}$ & $\mathbf{F}$ & Surveillance & Shame & Control \\
\hline Ethnicity & 3 & 2.05 & .96 & .79 & $4.07^{*}$ \\
Surgery (Yes/No) & 3 & 1.34 & $4.03^{*}$ & .74 & .67 \\
BMI & 3 & $3.00^{*}$ & .28 & $7.80^{*}$ & .08 \\
Income & 3 & $2.70^{*}$ & 1.13 & 2.08 & $5.57^{*}$ \\
E x S & 3 & .47 & .66 & .10 & .38 \\
\hline Note: $* \mathrm{p}<0.05, * * \mathrm{p}<0.01$ & & & &
\end{tabular}

\section{Ethnicity on Body Objectification}

The MANOVA with three levels of surgical intervention indicated a non-

significant multivariate main effect for ethnicity, Wilk's $\lambda=.89, F(3,54)=2.35, p=.08$,

thus failing to reject the null hypothesis that there is no difference between African

Americans and Caucasians on a linear combination of Body objectification factors.

There were also no significant Univariate effects for the OBC subscales

surveillance, Shame, or control. The interaction among ethnicity and type of surgery also 
failed to reach significance, indicating no differences found when combining the effects of ethnicity and type of procedure, Wilk's $\lambda=.93, F(3,54)=.68, p=.67$.

The second MANOVA (Table 4) including the dichotomized surgery variable found no main effect for ethnicity in this analysis ( $p=.12)$; however, there were two significant main effects for control variables. The main effect for income Wilk's $\lambda=.87$, $F(3,56)=2.70, p<.05$ indicates differences along income levels and a linear composite of Body Objectification factors. A significant univariate finding existed between Income and Body Control, $F(1,64)=5.57, p=.02$, thus indicating that as income increases so do women's feelings of control. The second significant main effect was on BMI Wilk's $\lambda=$ $.86, F(3,56)=3.00, p=.04$, indicating differences between BMI and the linear combination of Body Objectification factors. There were significant effects of BMI on Shame, $F(1,64)=5.39, p<.01$; thus, as BMIs increased women endorsed higher feelings of shame.

There was a significant univariate finding for ethnicity and body control. Ethnicity and control were significantly related, $\mathrm{F}(1,63)=4.07, p<.05$, with African American women endorsing higher Body Control $(\bar{x}=4.62, \mathrm{SD}=.71)$ than Caucasian women $(\bar{x}=4.14, \mathrm{SD}=.67)$. There were no significant differences between ethnicities for Surveillance $(p=.39)$, or Shame $(p=.20)$.

\section{Type of Surgery on Body Objectification}

The MANOVA including three levels of surgical intervention indicated a nonsignificant main effect for type of surgery, Wilk's $\lambda=.90, F(3,54)=.97, p=.45$, thus 
failing to reject the null and indicating no difference between degrees of surgical intervention on Body objectification. There were no significant univariate effect.

Similarly, when the cosmetic surgery variable was dichotomized, a nonsignificant main effect was observed, Wilk's $\lambda=.93, F(3,56)=1.34, p=.27$ (see Table 4). No difference was observed between women who have undergone any cosmetic procedure and controls on Body objectification. However, a significant finding emerged for the univariate analysis indicating significant effects of surgery on surveillance, $F$ $(1,63)=4.03, p<.05$. Women who had any cosmetic procedure $(\bar{X}=4.06, \mathrm{SD}=1.07)$ surveyed their bodies more closely that women who had no procedure $(\bar{x}=3.61$, $\mathrm{SD}=.70)$. 


\section{Chapter 4}

\section{Discussion}

The present study is the first to investigate the effects of cosmetic procedures and ethnicity on body objectification. Many authors have communicated the pressure women experience in meeting feminine beauty ideals (Backman \& Dams 1991; Bartky, 1990; Bartky, 1988), with many describing the particularly deleterious effects beauty norms have on African American women (Patton, 2006; Evans \& McConnell, 2003; Jones \& Shorter-Gooden, 2003; Hall, 1995; Hurtado, 1989). Being perceived as beautiful is valuable in all modern societies and can equal increased social mobility and success (Langlois et al., 1987; Langlo \& Kalakanis, 2000; Marlowe, Schneider, Nelson, 1996). An examination of the importance placed on beauty, those who fall outside of the beauty norm are thought to be immobile and unsuccessful. African American women typically have been seen as falling outside the Euro-American beauty norm and utilize within group comparisons insulating them from external norms (Patton, 2006; Frisby, 2004; and Evans \& McConnell, 2003).

There was no significance reached in this study but some interesting univariate significance emerged. Income maintained a significant relationship with Body Control, it was seen that higher levels of education was related to increased feelings of Body Control over their appearance. BMI had a significant univariate effect on Shame with higher BMIs being associated with higher levels of Shame.

In the second analysis, utilizing the dichotomized surgery variable, ethnicity and cosmetic surgery exhibited a positive univariate result. African American and Caucasian 
women differed on their endorsements of perceived control over the appearance of their bodies. African American women were found to have higher endorsements of control over their bodies when compared to Caucasian women. Commensurate with previous studies African American women typically have different definitions of beauty with larger body types and more masculine definitions of beauty. These divergent definitions may lead to increased feelings of control. There have been very few studies investigating perceived control over one's body among African American women, and it is an area of needed exploration.

Considering the importance of beauty in social mobility within modern societies there can be the assumption that women will go to great lengths to achieve the "ideal" beauty. Thus, elective cosmetic procedures become viable options. There were no differences between cosmetic surgery groups on Body objectification. However, when the cosmetic surgery variable was dichotomized significant univariate effects emerged for Body Control variables income and BMI as well as Control, and plastic surgery. Simply stated women who had an elective cosmetic surgery endorsed higher incidences of surveillance or self-observation than women who had never had any procedure. This finding is tentative considering the multivariate effect was non-significant.

With cosmetic surgery on the rise the Board of Certified Plastic Surgeon Resource found trending in procedures obtained by African American women. They identified the top three procedures as nose reshaping, liposuction, and breast reductions (2005). The top three procedures for African Americans in this study were; microdermabrasion, breast reductions and liposuction or tummy tucks. These findings are closely mirroring those found by the Board of Certified Plastic Surgeon Resource. 
Each of the top three procedures in this study are phenotypically linked to ethnicity with microdermabrasion linked to skin appearance, and breast reductions and liposuction linked to body size. Hall stated in her article that “...most Black people who wish to have cosmetic surgery do not necessarily desire White features; they simply wish to correct an unusual feature... They desire to 'preserve the ethnic character of the face while improving the aesthetic appearance of one or more features (1996, p130)." It is a common contention in current research that African Americans are more comfortable with aesthetic areas surrounding body size and type (Hall, 1996). This insulation and corresponding feelings of control over their bodies may be affecting the type of elective procedures chosen by African American women. However, additional research is needed to keep pace with the quickly developing social climate and ever increasing rate of African Americans receiving elective procedures. The trend seen here may be further illuminating the differences between ethnicities in their choices for appearance enhancing procedures.

\section{Limitations}

In this study there was a small sample size leading to reduced power, which was the likely cause of the lack of significant findings. Sixteen subjects elected to have at least 1 invasive procedure, 13 underwent a minimally invasive procedure and 35 had never had any procedure. However, when the surgery variable was dichotomized it was seen that 29 women had undergone an elective cosmetic procedure and 35 had not. The distribution of subjects was more even, thus creating a more reliable statistic.

A significant main effect was seen with income and may be explaining a portion of the variance of the study. Rather than there being differences between subjects 
because of ethnicity or procedure they are different by income. However, as the sample size increases the effect of income may be reduced. Power estimates were low with ethnicity measured at .74 and type of surgery was .43 . Alpha levels were also lower than those found in the seminal article written by McKinley \& Hyde. This study found alphas of .59 for surveillance, .62 for Shame, and .60 on Body Control.

Finding subjects for this study was difficult, considering the perceptions held toward cosmetic procedures and the privacy doctors maintain with their clientele. A number of high yielding private offices declined inclusion in the study because of concerns with privacy and misunderstandings of research procedure. Subjects were not monitored or proctored as they completed questionnaires, thus survey items could have been misinterpreted during administration or the instructions could have been given incorrectly at the hands of staff members. Thought the questionnaires were easy to read and could be completed while waiting for an appointment there was a low return rate. In future data collection increased incentives should be offered to doctors' offices as well as participants to increase returned surveys.

\section{Future Research}

Considering this is the first study to investigate the relationship between elective cosmetic procedures, ethnicity, and body objectification, additional larger-scale research is needed to further illustrate these relationships. As minority men and women increase in number among elective cosmetic procedure patients' mental health and surgeons need resources available to aid in their understanding and treatment of this population. With the trending away from exclusive physician care and a progression toward interdisciplinary treatment, psychotherapists fit a clear void in the treatment of these 
patients. Thus, research explaining the cultural implications of societal standards and pressures on minorities can prove invaluable in the consideration of ethnically diverse patients. If we placed a cultural lens on treatment and sound empirical evidence, we would be able to better serve minorities in the search of elective cosmetic procedures. 


\section{References}

A Board Certified Plastic Surgeon Resource. (2005). 2005 Plastic Surgery Statistics. Retrieved 9/19/2006 from http://www.aboardvertifiedplasticsurgeonresource.com/plastic_surgery/statistics.h tml.

American Society of Plastic Surgeons. 2005 Quick Facts: Cosmetic and Reconstructive Plastic Surgery Trends.2006

American Society of Plastic Surgeons. Dramatic Rise in Ethnic Plastic Surgery in 2005; ASPS reports procedures performed on Hispanics, Blacks up 67\%; Asians up 58\%. March 16, 2006.

Adamson, P. Changing perceptions of beauty: A surgeon's perspective. Facial Plastic Surgery; 2006; 22(3): 188-193.

Backman CB. Dams MC. Self-perceived physical attractiveness, self-esteem, race, and gender. Sociological Focus 1991; 24: 283-90.

Baker-Sperry L. Grauerholz, L. The Pervasiveness and Persistence of the Feminine Beauty Ideal in Children's Fairy Tales. Gender and Society. 2003; 17: 711-726.

Barden, R.C., Ford, M.E. Jensen, A.G., Rogers-Salyer, M., \& Salyer, K.E. (1989) Effects of craniofacial deformity in infancy on the quality of mother infant interactions. Child Development, 60, 819-824.

Bartky, S.L. Femininity and domination: Studies in the phenomenology of oppression. New York: Routledge. 1990.

Bartky S.L. Foucault, femininity, and the modernization of patriarchal power. Feminism and Foucault: Reflections on resistance 1988; Boston: Northeastern University Press.

Boyd-Franklin, N. Recurrent Themes in the Treatment of African American Women in Group Psychotherapy. Women and Therapy, 11, 25-40.

Breitkopf, C. R. Littleton, H., \& Berenson, A. (2007). Body Image: A study in a TriEthnic Sample of Low Income women. Sex Roles. 56: 373-380.

Buss DM. Sex differences in human mate preferences: evolutionary hypothesis tested in 37 cultures. Behavioral Brain Science. 1989; 12: 1-49. 
Buss DM. Shackleford TK. Kirkpatrick LA. Larsen RJ. A half century of Mate preferences: the cultural evolution of values. Journal of marriage and Family 2001; 63: 491-503.

Carver, CS. And Scheier, MF. Attention and self-regulation: A control theory approach to human behavior, 1981; New York: Springer-Verlag.

Constanzo, P.R. External Socialization and the Development of Adaptive Individuation and Social Connection. In D. N. Ruble, P.R. Constanzo, \& M.E. Oliveri (eds). The Social Psychology of Metal Health p. 55-80. New York: Guilford.

Crocker J. Major, B. Social stigma and self-esteem: The self-protective properties of stigma. Psychological Review 1989; 96: 608-630.

Deutsh FM, Zalenski CM. Clark ME. Is there a double standard of aging? Journal of Applied Social Psychology 2002; 2: 16: 77-85.

Evans PB. McConnell, AR. Do racial minorities respond in the same way to mainstream beauty standards? Social comparison processes in Asian, Black, and EuroAmerican women. Self and Identity 2003; 2: 153-167.

Fiengold A. Gender differences in effects of physical attractiveness on romantic attraction: a comparison across five research paradigms. Journal of Personality and social psychology. 1990; 59: 981-93.

Fredman Rita. 1986. Beauty Bound. Lexington, MA: Lexington Books.

Frisby, CM. Does Race Matter? Journal of Black Studies 2004; 34(3): 323-347.

Gangstad SW. Buss DM. Pathogen prevalence. Ethol Sociobiol 1993; 14: 89-96.

Gangestad SW. Scheyd GJ. The evolution of human physical attractiveness. The Annual review of anthropology 2005; 34:523-48.

Hall, C. Beauty is in the soul of the beholder: Psychological implications of beauty and African American women, Cultural diversity and mental Health, 1995, Vol. 1, No. 2, p. 125-137.

Hamermesh DS. Biddle JE. Beauty and the labor market. American Economic Reb. 1994; 84: 1174-94.

Harris, S. Racial Differences in Predictors of College Women's Body Image Attitudes. Women and Health, 1994, 21. 89-104.

Hedley, A., Orgden, C., Johnson, C., Carroll, M., Curtin, L., \& Flegal, K., Prevalance of Overweight and Obesity Among US Children, Adolescents, and Adults, 1999- 
2002. JAMA: Journal of the American Medical Association, 2004; 291(23), 28472850 .

Hurtado, A. Relating to privilege: Seduction and rejection in the subordination of EuroAmerican women and women of color. Signs, 1989; 14: 833-855.

Jones, C.; Shorter-Gooden, K. (2003) Shifting the Double Lives of Black Women in America, New York: Harper Collins.

Lewis, M. Shame: The Exposed Self. 1992; New York: Free press.

Langlois JH. Roggman LA. Casey R. Ritter JM. Rieser-Danner LA. Jenkins VY. Infant preferences for attractive faces: rudiments of a stereotype. Developmental Psychology 1987; 23: 363-369.

Langlois, J. H., Kalakanis, L., Rubenstein, .J., Larson, A., Hallam, M., \& Smoot, M.(2000). Maxims or Myths of Beauty? A Meta-Analytic and Theoretical Review. Psychological Bulletin. Vol 126, 3, p390-423.

Marlowe CM. Schneider SL. Nelson SE. Gender and attractiveness biases in hiring decisions: are more experienced managers less biased? Journal of Applied Psychology 1996; 81:11-21.

McKinley, N. The developmental and Cultural Contexts of Objectified Body Consciousness: A Longitudinal analysis of Two Cohorts of Women. Developmental Psychology. Vol 62, No 4, p. 679-687.

McKinley NM. Hyde, JS. The objectified body consciousness scale development and validation, Psychology of Women Quarterly. 1996; 20(2): 181-215.

Molloy, B. L., \& Herzberger, S.D. (1998). Body Image and self esteem: A comparison of African-American and Caucasian women. Sex Roles, 38, 631-643.

Muldoon OT. Social group membership and self-perceptions in Northern Irish children: a longitudinal study B Journal of Developmental Psychology. 2000; 18: 65-80.

Parker, S. Nichter, M., Nichter, N., Vuckowic, N., Sims, C., \& Ritenbaugh, C., (1995). Body Image and Weight Concerns Among African American and Euro-American Adolescent Females: differences that make a Difference. Human Organizaition, $54,103-114$.

Patton, T. O., (2006) Hey Girl, Am I More than My Hair?: African American Women and their Struggles with Beauty, Body Image, and Hair, NWSA Journal 18(2): 2451 . 
Poran, M.A. (2002) Denying Diversity: Perceptions of Beauty and Social comparison Processes Among Latina, Black, and Euro-American Women. Sex roles. 47. July 67-81.

Sarwer DB. Magee L. Cark B. Physical appearance and cosmetic medical treatments: physiological and socio-cultural influences. Journal of Cosmetic Dermatology. 2003; 22: 29-39.

Singh D. Adaptive Significance of female physical attractiveness: role of waist to hip ratio. Journal of personality social Psychology 1993; 65: 456-66.

Spitzack, C. Confessing Excess: women and the politics of body reduction. 1990 Albany NY: State University of New York Press.

Stephan CW. Langlois H. Baby Beautiful: Adult attributions of infant competence as a function of infant attractiveness. Child Development 1984; 55:576-85.

Symons D. The Evolution of Human Sexuality. New York: Oxford University Press: 1979.

Thornhill R. Gangestad SW. Human Facial beauty: averageness, symmetry, and parasite resistance. Human Nature 1993: 4: 237-69.

Thornhill R. Gangestad SW. Human Fluctuating asymmetry and sexual behavior. Psychological Science 1994; 5: 297-302.

Unger R.K. Female and Male. 1979; New York: Harper and Row.

Wallace, M. (1979). Black Macho and the Myth of the Superwoman. New York: The Dial Press.

Wolf, N. (1991). The Beauty Myth: How Images of Beauty are used Against Women. New York: Doubleday.

Zebrowitz LA. Olson K. Hoffman K. Stability of baby faces and attractiveness across the lifespan. Journal of personality and Social Psychology. 1993: 65:453-66

Zinn, M. (1990). Family, Feminism, and Race in America. Gender and Society, 4, 68-82

Zuckerman, M., \& Kieffer, S.C. (1994). Race differences in facieism: Does facial prominence imply dominance? Journal of Personality ad Social Psychology, 66, 86-92. 


\section{Appendix A}

\section{Informed Consent}

\section{The Promise of Happiness: \\ Women's Feelings about their Bodies and Elective Cosmetic Procedures}

\section{Purpose and Procedure}

You are invited to participate in a research study examining women's views of their body and how their views relate to cosmetic surgery. In order to participate, you will need to be a 19-to-70 year old female who has had either a surgical or non-surgical cosmetic procedure, or has never considered having an elective cosmetic procedure. This study is conducted by Allycin Powell-Hicks of Loma Linda University under the supervision of Dr. Gloria Cowan, adjunct Professor of Psychology at Loma Linda University. If you agree to participate in this study, you will complete a survey containing questions concerning feelings you hold about yourself and your body, cosmetic procedures you have had, and basic information about yourself. This survey will take approximately 15 minutes to complete. If you are taking this survey at a medical office deposit it in the receptacle marked for this study. Locations other than medical offices will also provide a clearly labeled receptacle for you to deposit your questionnaire.

\section{Risks}

It is expected that your involvement in this study will not create any significant risks to you. Some of the questions in the survey are personal and may raise issues regarding your self-appraisal and may be embarrassing. If you feel a question is too difficult or uncomfortable to answer, you may skip that question.

\section{Benefits}

You will not receive any direct benefit from your participation in this research study other than the educational experience of participating in a scientific psychological research project. It is anticipated that the results of this study will help advance our understanding of how women's feelings about their body and feelings of control over their appearance are related to their decision to obtain cosmetic surgery.

\section{Confidentiality}

All of the information gathered during your participation in this research study is anonymous. Do not write your name or any information that will identify yourself on this survey, and the information you provide will be grouped with that of other participants. Any publications or presentations resulting from this study will refer only to the grouped results. 


\section{Third Party Contact \& Participant's Rights}

If at any time you have any other questions regarding your participation in this study, you should feel free to contact the principle investigator, Dr. Gloria Cowan, $\mathrm{PhD}$ at (310) 823-6421 or Allycin Powell-Hicks at (714) 998-9312.

If you wish to contact an impartial third party not associated with the study regarding any complaint about he study, you may contact the Office of Patient Relations, Loma Linda university medical Center, Loma Linda, CA 92354 (909) 558-4647, for information and assistance.

Participation in this study is voluntary and if, after marking this consent form, you decide to discontinue the session at any time, for any reason, you are free to do so. Declining to participate in this study will have no affect on the quality of treatment you receive. If you have any questions regarding this study, we will be happy to answer them.

\section{Consent Statement}

I have read the contents of this consent form and have been given the opportunity to ask questions concerning this study. I have been provided a copy of this form. I hereby give my voluntary consent to participate in this study. Marking this consent document does not waive my rights nor does it release the investigators or institution from their responsibilities. I may call Dr. Gloria Cowan at (310) 823-6421 if I have additional questions or concerns.

Please do not put your name on the questionnaire.

Please place a check or ' $x$ ' in the space provided below to acknowledge that you are at least 19 years old and have read and understand the material explained above. Also, by marking the space below you have given your consent to participate voluntarily in this study.

Please check here:

Date: 